\title{
MEDICINA LEGAL
}

\section{DOCUMENTOS INTERESASTES}

Publicamos, en estas páginas, dos documentos médico legales del mayor interés.

Es el primero el informe elevado a la Facultad de Medicina de Lima por su catedrático de Medicina l.egal $\mathrm{y}$ Toxicología Dr. Leonidas Avenda. non, respecto a la situación inaceptable creada para la institución por obra del inspirador del Codigo de Procedimientos en Materia Penal. Sin un conocimiento mediocre de las más altas finalidades de la Facultad de Medicina de Lima, con desconocimiento absoluto de los elementos materiales a. portados por el Estado a la obra docente que la Facultad, realiza, el inspirador del dicho Código, cuya obra ectopica $y$ auacrónica ba sido objeto de tantas críticas, en el ambiente jurídico como en el médico, ha impuesto a la Facultad de Medicina, a título gratuito, obligaciones que los códigos extranjeros asignan a instituciones de urgatiización y finalidades diversas.

El luminoso informe del Prófesor Arendaño hace merecida crítica del citado Codigo e ilustra el estudiodel asunto.

El segundu documente sé sefiere a casos de intoxicación por el aceite de quenopodio, que alaimaron justamentc a la sociedad de Lima, por la gravedad mortal de los accidentes que siguieron a la administración de ese medicamento. Es el informe pericial emitido por el Dr. Guillermo Almenara y por el Farmacéutico Sr. Manuel Fernández Larrea.

Lima, 27 de agosto de 1923.

Señor Decano de la Facultad de Medicina.

S. D.

El señor Juez Instructor de la Provincia del Callao, en oficio dirigido a ese Decanato con fecha 4 del presente mes 
de agosto-oficio que Ud. ha tenido a bien trascribirme en 22 del mismo mes--solicita de la Facultad de Medicina, que esta corporacion verifique el análisis toxicológico de las víceras y líquidos extraídos del cadáver del Dr. Augusto Durand: solicitación que hace de conformidad con lo dispuesto en el Art. 143 del Codigo de Procedimientos en Materia Criminal, en el que se preceptúa que la Facultad de Medicina debe practicar gratuitamente los referidos análisis.

No es esta la primera vez que la autoridad judicial quiere imponer a la Facultad de Medicina una obligación incompatible con su independencia, con su organización y con su finalidad; ni támpoco será esta la vez primera que la Facultad se inhiba de tal encargo, porque no le corresponde en modo alguno intervenir, a unque sea en minima parte, en las tramitaciones judiciales, pese a lo inconsultamente determinado en el código de la materia.

Pero como quiera que las alegaciones otrora expuestas por la Fácultad, en defensa de sus legitimos derechos, son a las veces desconocidas for algunos miembros del poder judicial, como sucede en el presente caso, me parece oportuno indicar a continuacion las poderosas razones que fundamen. tan la negativa de la Frcultad para aceptar el papel de auxiliar gratuito de la administración de justicia; y, en las que me apoyo personalmente, para no reconocer en átutoridad alguna derecho para imponerme un trabajo a título de gratuito.

Lá Facultad de Medicina, encumbrada corporación offcial, dependencia principalísima de la Universidad Mayor de San Marcos, es un organismo ducente, encargado exclusivamente de enseñar todas las ramas principales y accesorias de las ciencias médicas; y, de educar, con sujeción a los cánones de la pedagogía y de la deontología nédicas, a los jovenes que aspiran a ser profesionales medicos; a los que otorga, finalizados sus estudios, título de suficiencia, que los capacita para recibir de la autoridad respectiva licencia para ejercer la noble y altruista profesión médica. A esta fnalidad, la enseñanza de las ciencias médicas y su metódico a prendizaje, es a la única que debe dedicar sus energías y sus recursos de todo género la Facultad de Medicina; pues incurriría en muy grave responsabilidad si distrajera los escacísimos recursos de que dispone, en sus laboratorios, en otro objeto que la enseñanza práctica de sus alumnos.

La constitución de la Facultad de Medicina, y toda la 
Universidad de Lina, está debidamente puntualizada en la Ley Orgánica de Enseñanza, de 30 de junio de 1920, en cuyo articulado se detalla u las a tribuciones y las obligaciones de todas las Facultades en general, y de la de Medicina en particular. Y en ninguno de los diecisiete incisos del artículo 295 de la referida ley, en que se especifican las atribuciones de las Facultades de la Universidad, se consigna nada que tenga relación con el contingente que deban prestarestas instituciones al Poder Judicial en la instrucción de las causas criminales; $-\mathbf{y}$, en los artículos 385 y 391 , se estatuye que la Facultad de Medicina, confiere el título de Médico y Cirujano, y otorga el título de obstetriz, a los que satisfacen los requisitos respectivos; sin que ni por asomo se preceptúe nada que pueda referirse a la pretensión del Sr. Juez instructor del Callao. X como muy poderoso argumento, vale la pena recordar, que habiéndose puesto en vigencia el Código de Procedimientos en Materia Criminal el 18 de marzo de 1920, y promulgádose la Ley Ge Enseñanza vigente, posteriormente, el 30 de junio de 1920 , no se modificó en lo menor la tradicional organización de la Facultad de Medicina, entre cuyas obligaciones nunca hal figurado las que le quiere imponer el código de procedimientos criminales. Como se ve, pues, en lá Ley Orgánica de Enseñanza, que es el código privativo que norma los procedimientos de las Facultades de la Universidad Mayor de San Marcos, no hay precepto alguno que obligue a la Facultad de Medicina a desempeñar la comisión que quiere conferirle un juez de instrucción: Practicar gratuitamente una seria y bien laboriosa investigación toxicologica. Y como la Ley de ensenanza se puso en vigencia con posterioridad al momento en que comenzó a regir el Código de Procedimientos en Materia Criminal, es indiscutible que las prescripciones de este Gltimo no pueden en modo alguno variar sustancialmente las de la primera.

$\mathrm{Y}$ es no solo la ley escrita, la que justifica la nega tiva de la Facultad de Medicina a someterse a las no muy bien meditadas disposiciones judiciales; también le sirven de apoyo los eternos e inmutables principios de la justicia universal. Sería, en electo, clamoroso e inconcebible, señor Decano, que de todos los que actán en el intrincado mecanismo judicial, desde el Señor Presidente del Tribunal Supremo hasta el altimo alguacil, fuerán sólo la Facultad de Medicina y sus catedraticos los obligađos a prestargratis sus servicios. Aque. 
llo significaría colocar a los profesores de la Facultad de Medicina y a ésta en servil e irritante condición: sería desconocer los respetos y consideraciones que nos merecemos: sería una grave falta de consideracion, contra la que hay que protestar con entereza y dignidad. La Facultad de Medicina y sus miembros están colocados en un plano superior de aquel en que quiere situarlos el Código de Procedimientos en Materia Criminal.

No vaya a creerse que por el hecho de inhibirse la Facultad de Medicina de verificar el análisis solicitado, queda privado el Poder Judicial del valioso concurso de la ciencia médica: no, señor Decano, pues hay otros organismos intelectuales a quienes, por precepto expreso de la ley, compete tal obligación. De conformidad con lo dispuesto en el Art. $2^{\circ}$ de la ley de 2 de noviembre de 1888, la Academia Nacional de Medicina, ejerce: "las funciones de cuerpo consultivo de los Poderes Páblicos en asuntos profesionales", pudiendo el Sr. Juez instructor del Calla acudir a esa institución, siempreque le proporcione los elementos materiales (un bien montado laboratorio de toxicologia) de que carece actualmente. $Y$ en el Art. $2^{\circ}$ del Supremo decreto de 2 de febrero de 1923 , que determina la nueva organización del servicio médico legal, se estatuye: "El Cuerpo Médico Foruse de Lima se considerará como corporación consultiva en toda clase de asuntos nédicos legales"; y, como en ese cuelpo hay una sección, la tercera, de Quínica y Biología, es a ese cuerpo al que debe pedir el Sr. Juez del Calláo el concurso que necesita: pues ha sido creado para remedia las deficiencias que siempre han existido en el servicio médico legal.

Paso a contemplar la segunda parte de esta cuestión: la que se refiere exclusivamente a mi persona, sea como Catedrático titular de la Facultad, o como simple profesional médico que ejerzo con sujeciôn a las leyes $y$ reglamentos vigentes. Ni como cátedrático, ni como médico particular, tengo obligación de aceptar a título gratuito el cargo de perito que quiera encomendarme cualquiera autoridad judi. cial: Como profesor de la Facultad, mis obligaciones están claramente determinadas en el Ait. 333 de la Ley Orgánica de Enseñanza, que no preceptra nada sobre peritajegratuito en los siete incisos de que se compone el referido artículo; y, como simple particular mi derecho está amparado por el Art. 38 de la Constitución del Estado, que dice: "La propiedad es inviolable, bien sea material, intelectual, literaria o 
artística. A nadie se le puede privar de la suya sino por causa de utilidad pública probada legalmente y PREVIA INDEMNIZACION JUSTIPRECIADA". Esta preciosa garantía que la CONSTITUCION otorga a todos los ciudadanos, no puede ser invalidada por una ley secundaria; $y$, por tanto, no existe poder alguno que pueda imponerne el trabajo, mi propiedad intelectual, sin la remuneración correspondiente.

Ahora bien; en el improbable supuesto, que ni siquiera puede presumirse, de que la Facultad accediera a la solicitación del Sr. Juez del Callao, siempre tendría éste la obligación de abonarme mi honorario como perito: honorario que estimaría en este caso en la suma de Cien Libras Peruanas (Lp. 100.0.00), pagaderas por adelantado; pues no Jeseo volver a engolfarme en los eternos trámites a que obliga la cobranza después de efectuada la operación médico legal, que en algunos casos nunca puede hacerse ffectiva.

Es cuanto puedo y debo decir a Ud., Sir. Decano, con motivo del pedido hecho por el Sr. Juez instructor le la provincia del Callao. ['a. resolverá lo que le partzcá más conveniente, teniendo en cuenta las razones expusistas.

Saludo con todá consideración al Sr. Decano, a quien Dins gue.

(Firmádo)--L. AvENDAÑo.

Señor Juez del Crimen:

Los suscritos doctor Guillermo Almenara y farmacéutico Manuel Fernández Larrea, nombrados peritos por usted para dictaminar en la instrucción que se sigue contrá don Karl Winkler, por el delito de intoxicación, acerca del contenido de dos cápsulas de aceite de quenopodio y acerca de que si el aceite de quenopodio puro suministrado a un niño de diez años en lá forma de: Primer día, a $7 \mathrm{~h}$. una cápsula después del desayuno acostumbrado; a las 9 h. una cápsula; a las 11 una cápsula. Segundo día, como el primero. Tercer día como el primero y segundo, después dos cucharadas de aceite de ricino, constituye o nó un tóxico capaz de causar la muerte, debemos informar lo siguiente:

Las dos cápsulas de aceite de quenopodio recibidas te- 
nían un peso exacto, una de un gramo cuatrocientos ochentaicinco milígramos y la otra de un gramo cuatrocientos ochentaiocho miligramos. Son de las llamadas cápsulas gelatinosas que se usan corrientemente para la administracion de medicamentos. El contenido de cada una era de un centí. metro cúbico, dos décimos, de un aceite a marillo claro, transparente, de olor penetrante, característico del aceite de quenopodio, de sabor picante. algo amargo. Las investigaciones realizadais nos permiten decir que aparte del aceite de quenopodio contienen dichas cápsulas, aceite de pepita de algod $6 \mathrm{n}$. Aunque la pequeñez de la muestra remitida para su estudio no ha permitido verificar ensayos químicos cuantitativos, el estudio de la densidad en comparacion con la de mezclas preparadas por nosotros de aceite de quenopodio y aceite de pepita, nos ponen en el caso de decir que ambos componentes están en partes iguales, por cada cápsula: 10 mininas de aceite de quenopodio y 10 minimas de aceite de pepita, aproximadámente; proporción que, por lo demás, es la misma que indica el fabricante del producto, que es la conocida firma norteamericana $H$. K. Mulford y Compañia. Estás cápsulas de aceite de quenopodio son las que se usan corrientemente en medicina para la expulsión de los gusanos intestinales y en especial del llamado Ankilostoma.

El aceite de quenopodio es un producto altamente tóxico, ejerciendo su acción preferentemente sobre el sistema nervioso central. Su absorcion comienza pocas horas despues de haber sido ingerido y la intoxicación se manifiesta por un síntoma precursor, la somnolencia, que indica la necesidad de hacerlo evacuar inmediatamente. Pasado este periodo precursor y no habiéndose evitado la aparición de los otros fenómenos tóxicos que le siguen, es muy difícil conseguir la restauración del entermo. Circunstancia notable es la de que el aceite de quenopodio tiene la propiedad de acumularse, es decir, de eliminarse muy lentamente: la dosis terapética es eliminada en un plazo que dura al rededor de diez días. Este medicamento se usa, como decimos más arriba para hacer expulsar los gusanos intestinales y en especial el llamado Ankilostoma y su semejante el Necator a mericano.

Para el aceite de quenopodio así como pasa con otros medicamentos, algunos individuos tienen intolerancia especial; intolerancia que es más marcada en los niños, sobre todo cuando han pasado éstos, anteriormente, una enfermedad caquectizante, o consuntiva. 
En el adulto la dosis recomendada es la de un centimetro cúbico y medio, dada en dos mitades o de una vez, las dos mitades con intervalo de dos horas y seguidas, después de dos horas, de un purgante suficiente para hacer arrojar los gusanos narcotizados por el medicamento y el exceso de éste que pudiera absorverse. La dosis máxima de tres centímetros cúbicos que estaba permitida para el adulto, hoy día casi está proscrita, por los peligros que ella entrâna y por las consecueacias o malestares que deja en el paciente.

Para los niños la dosis recomendable es de una gota por año de edad $(0.066 \mathrm{cc})$ dada en dos mitades o de una vez, pero seguida siempre de un purgante. La dosis máxima, no recomendable y peligrosa es de dos gotas por año de edad. La mayor parte de los casos fatales que cita la literatura médica se observáron en niños que tomaron conforme a esta dosificación. La intolerancia especial de los niños para este medicamento, obliga al médico a una vigilancia cuidadosa para atenderlos con los recursos conocidos desde la aparición del síntoma precursor o de otra manifestación de orden tóxico.

De acuerdo con la particula ridad ya anotada cual es la de acumularse el aceite de quenopodio en el organismo, la posología del medicamento aconseja que después del trata. miento de un día y con la dosis permitida y el purgante respectivo, solo podrá repetirse el tratamiento diez días después, siempre y cuando la primera administración no haya producido manifestaciones de intolerancia, que son, aparte de la somnolencia, la sordera, los desfallecimientos, los hor. migueos en las extremidades, la irritación del estómago, etc.

Después de todo lo expuesto, estamos autorizados para las siguientes conclusiones:

$1^{\circ}$.-Que las cápsulas remitidas para su estudio contienen, cada una, 0,6 (seis décimas de cc.) de aceite de quenopodio y 0,6 (seis décimas de centimetro cúbico) de aceite de pepita de algod $6 n$, o sean aproximadamente, diez mínimas de aceite de quenopodio ( $\mathrm{X}$ gotas) y diez mínimas de aceite de pepita de algodón. El producto activo es aquí el aceite de quenopodio.

$2^{9}$.-Que la dosis de treinta mínimas (el contenido de las tres cápsulas recetadas por cada día) para un menor de diez años, en un tratamiento, es una dosis exagerada y altamente tóxica. Un niño de esa edad podría llegar a tomar, forzando la dosis maxima, y siempre seguida de un purgante, 
hasta veinte mínimas, nunca más, y eso exponiéndose a la toxicidad del medicamento.

$3^{\circ}$.-Que la repetición del tratamiento por tres días seguidos, está totalmente contraindicada conocida la propiedad de acumularse que tiene el medicamento de que tratamos.

$4^{\circ}$.- La falta de un purgante después de los tratamientos suministrados en los dos primeros días, agravó la situación tóxica que ya tenía la excesiva dosis prescrita.

Por consiguiente el tratamiento formulado para un menor de diez años de treinta mínimas de aceite de quenopodio por tres días seguidos, es un tratamiento inusitado, se aparta por completo de lo que la medicina aconseja y puede perfectamente haber producido la muerte del niño de diez años a quien fué destinado.

Es cuanto tenemos que informar a usted Señor Juez.

(Firmado)-Guillermo Almenara.

Manuel Fe ruández Larrea. 